Vietnam Journal of Mechanics, NCST of Vietnam Vol. 24, 2002, No3 (167 - 180)

\title{
WAVES REFLECTED BY SOLID WALL IN THE MIXTURE OF LIQUID WITH VAPOUR BUBBLES
}

\author{
DUONG NGOC HAI \\ Institute of Mechanics, 264 Doi Can, Hanoi, Vietnam \\ NGUYEN VAN TUAN \\ University of Industrial Engineering Thainguyen, Vietnam
}

\begin{abstract}
The liquid and gas mixtures are met in many natural and industrial processes. In the paper the results of investigation of waves reflected by solid wall of the stationary shock waves with moderate intensities or the transient pulses propagated in the mixture of liquid with vapour bubbles are presented. The effect of initial conditions, shock strength, size of the bubbles and volume fraction of vapour phase on the behaviour of the waves reflected by solid wall is studied.
\end{abstract}

\section{Introduction}

It is well known that the presence of bubbles of gas or vapour in a liquid considerably alters the character of the propagation of pressure waves through the liquid. This fact has important implications in energy industry, in associated with nuclearreactor technology, in the oil exploitation, transportation and processing industry and in chemical engineering and many natural processes (Fujii et al -1991; Dontsov et al - 1998).

Shock waves in liquid with bubbles of an insoluble and non-condensable gas have been investigated theoretically and experimentally by Noordzij \& Wijngaarden (1974); Nigmatulin, Khabeev \& Shagapov (1974); Nigmatulin \& Shagapov (1974); Drumheller, Kipp \& Bedford (1982). Experimental study of gas solution process behind a shock wave in liquid with bubbles of easily soluble gas has been investigated theoretically and experimentally by Dontsov \& Pokusaev (1998). Shock waves in non-Newtonian bubbly liquids have been investigated numerically by Gubaidulin, Beregova \& Bekishev (2001). Liquid velocity and wall shear stress in bubbly flows have been investigated by Kashinsky, Radin \& Chinak (1998).

The propagation of waves in a liquid with vapour bubbles has been investigated by Duong Ngoc Hai, Nigmatulin \& Khabeev (1982); Nigmatulin, Khabeev \& Duong Ngoc Hai(1988); Duong Ngoc Hai (1987). An increase in the amplitude of pressure waves in a vapour-liquid mixture with bubble structure has been investigated by Nakoryakov, Vasserman, Pokusaev \& Pribaturin (1994). An experimental investigation of structure of stationary shock wave and its interaction with transient impulse of pressure in two-phase flow has been investigated by Kwidzinski, Karda 
\& Pribaturin (1998).

Let us consider a mixture of liquid and vapour bubbles which, for example, is held in a pipe. A stationary shock wave propagates in the mixture to a closed pipe valve and reflects backwards from it. The valve is supposed to be made of a perfectly solid material. Although mass of the vapour phase is normally much less than that of the mixture, but the existence of vapour phase can completely change the motional and physical features of the medium. Therefore, the influences of the vapour phase of the mixture, such as volume fraction, bubbles radius and initial shock intensity on the behaviour of the reflection waves, the wave propagation velocity and etc., after being reflected from the solid wall (the closed pipe valve), will be considered in this paper.

\section{Assumptions, symbols and basic equations}

Wave processes in a bubbly liquid are considered here using continuum-mechanics methods under the following basic assumptions:

a) The distances over which the flow parameters (for example, oscillatory wavelengths) vary significantly are much larger than the bubbles diameters (i.e. the volume fraction of the vapour phase is small enough, $\alpha_{2} \leq 0.1$ );

b) The mixture is locally monodispersed and all bubbles are spheres with the same radius;

c) Viscosity and thermal conduction are only important in the processes of interphase interactions and particularly in bubble pulsations;

d) The motion processes of mixture, nucleation, fragmentation, interaction, and coagulation of the bubbles are absent;

e) The velocities of the macroscopic motion of the phases are the same;

The last assumption allows us to describe bubble volume changes, temperature distributions around the bubbles, condensation and evaporation in terms of spherically symmetrical model using the equations for bubble radial pulsations and radial thermal conduction of the liquid.

Under the assumptions listed above the vapour-liquid medium can be considered within the framework of a model of the carrier liquid and the vapour phase. In the Lagrangian system of coordinates $(x, t)$ the equations of conservation of mass, bubble number density and motion are expressed as follows (Nigmatulin - 1990):

$$
\begin{aligned}
& \frac{\partial \rho_{1}}{\partial t}+\frac{\rho \rho_{1}}{\rho_{0}} \frac{\partial v}{\partial x}=-4 \pi R^{2} n j \\
& \frac{\partial \rho_{2}}{\partial t}+\frac{\rho \rho_{2}}{\rho_{0}} \frac{\partial v}{\partial x}=4 \pi R^{2} n j ; \\
& \frac{\partial n}{\partial t}+\frac{\rho n}{\rho_{0}} \frac{\partial u}{\partial x}=0 \\
& \frac{\partial v}{\partial t}+\frac{1}{\rho_{0}} \frac{\partial p}{\partial x}=0
\end{aligned}
$$




$$
\begin{aligned}
& \rho_{i}=\alpha_{i} \rho_{i}^{0} ; \quad \alpha_{1}+\alpha_{2}=1 ; \quad \rho=\rho_{1}+\rho_{2} ; \quad \alpha_{2}=\frac{4}{3} \pi R^{3} n \\
& p=\alpha_{1} p_{1}+\alpha_{2}\left(p_{2}-\frac{2 \sigma}{R}\right),
\end{aligned}
$$

where the subscript $i=1,2$ refer to parameters of liquid and vapour, respectively. The subscript 0 refers to parameters of initial equilibrium state. $\alpha_{i}, p_{i}, \rho_{i}, \rho_{i}^{0}$ are the volume fraction, pressure, mean and true densities of the $i$-th phase, respectively. $v$ is the longitudinal velocity, $n$ is the number of bubbles per unit volume, $R$ is the bubble radius, $j$ is the rate of phase transition per unit interfacial surface $(j>0$ for evaporation; $j<0$ for condensation), $\sigma$ is the coefficient of surface tension, $x$ is the Lagrangian coordinate and $t$ is the time.

An equation for a change in the mass of individual bubble can be obtained from the equations of conservation of the mass of the vapour phase and the bubble number density as follows:

$$
\frac{\partial}{\partial t}\left(\frac{4}{3} \pi R^{3} \rho_{2}^{0}\right)=4 \pi R^{2} j
$$

The system of hydrodynamic equations (2.1)-(2.4) will be closed if the equation of state, the condition of the simultaneous deformation of the phases and the equation for determining the phase transition rate $j$ are assigned. The evolution of pressure waves of moderate intensities can be considered under the following additional assumptions:

g) The carrier liquid phase is incompressible:

$$
\rho_{1}^{0}=\text { const. }
$$

h) The vapour obeys the equation of state of a perfect gas, and being in the saturated state at the interface it obeys the Clapeyron-Clausius equation:

$$
p_{2}=B \rho_{2}^{0} T_{2} ; \quad \frac{d T_{2 \sigma}}{d p_{2 \sigma}}=\frac{T_{2 \sigma}}{\rho_{2 \sigma}^{0} \ell}\left(1-\frac{\rho_{2 \sigma}^{0}}{\rho_{1}^{0}}\right),
$$

where $T$ is the absolute temperature, $B$ is the gas constant, $\ell$ is the specific heat of vaporization, the symbol $\sigma$ refers to the parameters at the interface.

To determine the temperature, density and heat-flux distributions, we use the equation of discontinuity, heat condition and the equation of state. The vapour and liquid at the interface are assumed to be in thermodynamic equilibrium. The phase transition rate $j$ may be found from boundary conditions on the bubble surface. The boundary conditions at the bubble centre may be determined from the conditions of finite heat flux, temperature and density. In the absence of a macroscopic heat flux in the carrying phase, its cell boundary conditions should reflect the cell adiabaticity. The system of equations describing the distributions of the microparameters inside 
and around the test bubble and boundary conditions in the system of coordinates $(t, x, r)$ are displayed as follows:

$$
\begin{aligned}
& r>R: \quad \rho_{1}^{0} c_{1}\left(\frac{\partial T_{1}}{\partial t}+w_{1 \sigma} \frac{R^{2}}{r^{2}} \frac{\partial T_{1}}{\partial r}\right)=\frac{1}{r^{2}} \frac{\partial}{\partial r}\left(\lambda_{1} r^{2} \frac{\partial T_{1}}{\partial r}\right) \\
& r<R: \quad \rho_{2}^{0} c_{p_{2}}\left(\frac{\partial T_{2}}{\partial t}+w_{2} \frac{\partial T_{2}}{\partial r}\right)=\frac{1}{r^{2}} \frac{\partial}{\partial r}\left(\lambda_{2} r^{2} \frac{\partial T_{2}}{\partial r}\right)+\frac{\partial p_{2}}{\partial t} ; \\
& r=R: \quad T_{1}=T_{2}=T_{s}\left(p_{2}\right) ; \quad j \ell=-\left(q_{1 \sigma}+q_{2 \sigma}\right) ; \quad q_{1 \sigma}=-\lambda_{1}\left(\frac{\partial T_{1}}{\partial r}\right)_{r=R} ; \\
& j=\rho_{1}^{0}\left(\frac{\partial R}{\partial t}-w_{1 \sigma}\right)=\rho_{2 \sigma}^{0}\left(\frac{\partial R}{\partial t}-w_{2 \sigma}\right), \\
& r=R \alpha_{2}^{-\frac{1}{3}}: \quad \frac{\partial T_{1}}{\partial r}=0, \\
& r=0: \quad w_{2}=0 ; \quad \frac{\partial T_{2}}{\partial r}=0
\end{aligned}
$$

where $w_{2}$ is the velocity of radial motion of the vapour, $c_{p v}$ is the specific heat at constant pressure of the vapour, $\lambda$ is the thermal conductivity, $q_{1 \sigma}$ and $q_{2 \sigma}$ are the heat fluxes to the liquid and vapour, respectively, from the interface. Subscript $s$ refers to saturation.

In many cases (see, Nigmatulin et al 1988) for inside bubble heat problem, $q_{2 \sigma}$ can be calculated in terms of the model of a uniform bubble filled with saturated vapour. In this case, the equation of the heat flowing to the vapour phase (equation (2.9)) can be solved and this gives the following expression for $q_{2 \sigma}$ :

$$
q_{2 \sigma}=\frac{R}{3}\left[\frac{c_{p_{2}} T_{2}}{\ell}\left(1-\frac{\rho_{2}^{0}}{\rho_{1}^{0}}\right)-1\right] \frac{\partial p_{2}}{\partial t}=\frac{c_{s} T_{2}}{\ell} \frac{R}{3} \frac{\partial p_{2}}{\partial t},
$$

where $c_{s}$ is the vapour specific heat along the phase equilibrium curve:

$$
c_{s}=c_{p}-T\left(\frac{d p}{d T}\right)_{s} \frac{\partial}{\partial T}\left(\frac{1}{\rho}\right)_{p} .
$$

The pressure of the phases and the bubble radius are related through the conditions of simultaneous deformation as described by the Rayleigh - Plesset equation:

$$
\begin{aligned}
& \left(1+\varphi_{1}\right) R \frac{\partial w_{1 \sigma}}{\partial t}+1.5\left(1-\varphi_{2}\right) w_{1 \sigma}^{2}+\frac{4 \nu_{1}}{R} w_{1 \sigma}-\frac{2 j}{\rho_{1}^{0}}\left(1-\varphi_{1}\right) w_{1 \sigma}=\frac{1}{\rho_{1}^{0}}\left(p_{2}-p_{1}-\frac{2 \sigma}{R}\right) ; \\
& \frac{\partial R}{\partial t}=w_{1 \sigma}+\frac{j}{\rho_{1}^{0}}=w_{2 \sigma}+\frac{j}{\rho_{2 \sigma}^{0}} \\
& \varphi_{1}=\frac{3}{2} \frac{\alpha_{2}^{\frac{1}{3}}-\sigma_{2}}{1-\alpha_{2}} ; \quad \varphi_{2}=\frac{\alpha_{2}^{\frac{3}{3}}\left(2+\alpha_{2}\right)-3 \alpha_{2}}{1-\alpha_{2}},
\end{aligned}
$$

where $\varphi_{1}, \varphi_{2}$ are the corrections for collective effect and $\nu_{1}$ is the kinematic viscosity. 


\section{Results and discussion}

The system of differential equations (2.1)-(2.13) of the model is modified to a suitable form for numerical integration as follows:

$$
\begin{aligned}
\frac{\partial R}{\partial t}= & w_{1}+\frac{j}{\rho_{1}^{0}} \\
\frac{\partial w_{1}}{\partial t}= & \frac{1}{\left(1-\varphi_{1}\right) R}\left[\frac{p_{2}-p-\frac{2 \sigma}{R}}{\alpha_{1} \rho_{1}^{0}}-\frac{3}{2}\left(1-\varphi_{2}\right) w_{1}^{2}-\frac{4 \nu_{1} w_{1}}{R}-\left(1-\varphi_{1}\right) \frac{2 f}{\rho_{1}^{0}} w_{1}\right] \\
\frac{\partial \rho}{\partial t}= & -\frac{3 \rho \alpha_{2} w_{1}}{R} ; \\
\frac{\partial p_{2}}{\partial t}= & \frac{3 \gamma p_{2}}{\gamma_{*} R}\left(\left.\frac{\lambda_{1}}{\rho_{2}^{0} \ell} \cdot \frac{\partial T_{1}}{\partial r}\right|_{R}-\frac{\partial R}{\partial t}\right) \\
\frac{\partial T_{2}}{\partial t}= & \frac{T_{2}}{\ell \rho_{2}^{0}}\left(1-\frac{\rho_{2}^{0}}{\rho_{1}^{0}}\right) \frac{\partial p_{2}}{\partial t}=\frac{B T_{2}^{2}}{\ell p_{2}}\left(1-\frac{\rho_{2}^{0}}{\rho_{1}^{0}}\right) \frac{\partial p_{2}}{\partial t} ; \\
\frac{\partial^{2} p}{\partial x^{2}}= & \frac{1}{\rho_{0}} \frac{\partial \rho_{0}}{\partial x} \frac{\partial p}{\partial x} \\
& -\frac{3 \rho_{0}^{2} \alpha_{2}}{\left(1-\varphi_{2}\right) \rho R^{2}}\left\{\frac{1}{2} w_{1}^{2}\left(1-4 \varphi_{1}+3 \varphi_{3}\right)-w_{1} \frac{4 \nu_{1}}{R}+\frac{p_{2}-p-\frac{2 \sigma}{R}}{\alpha_{1} \rho_{1}^{0}}\right\} \\
\frac{\partial v}{\partial x}= & \frac{3 \rho_{0} \alpha_{2} w_{1}}{\rho R} ; \\
\frac{\partial T}{\partial r}+ & \frac{w_{1} R^{2}}{r^{2}} \frac{\partial T_{1}}{\partial r}=\frac{\lambda_{1}}{\rho_{1}^{0} c_{1}} \frac{1}{r^{2}} \frac{\partial}{\partial r}\left(r^{2} \frac{\partial T_{1}}{\partial r}\right)
\end{aligned}
$$

where $\gamma$ is the specific heat ratio.

The corresponding mathematical problems consisted in finding solutions of the system (3.1) - (3.8), subject to the following initial and boundary conditions:

$$
\begin{array}{ll}
t=0: & p_{1}=p_{0} ; \quad p_{2}=p_{0}+\frac{2 \sigma}{R_{0}} \\
& R=R_{0} ; \quad v=w_{1}=0 ; \quad T_{1}=T_{2}=T_{0} ; \\
x=0: & p=p_{e} ; \\
x=L: & p=\frac{\partial p}{\partial x}=0 .
\end{array}
$$

The propagation of short pressure delta-pulses was studied. For a delta-pulse the function $f(t)$ is of the form:

$$
f(t)= \begin{cases}p_{0}(1+b t) ; & t<t_{1}, \\ p_{0}\left[(1+b t)-b\left(t-t_{1}\right)\right] ; & t_{1} \leq t \leq t_{2}, \\ p_{0} ; & t_{2}<t,\end{cases}
$$


where the constants $t_{1}, t_{2}$ are determined by duration of the initial pulse, and the non-negative coefficient $b$ by its intensity. In general case $f(t)$ can be any function of time.

The system of equation (3.1) - (3.8) have been solved by a combination of the modified Euler method with the Thomas algorithm. The solution of this multiparameter problem is determined by the dimensionless numbers and combinations such as:

$$
\begin{aligned}
G & =\frac{g R_{0}}{a_{*}^{2}\left(\alpha_{20} \alpha_{10}\right)^{1 / 2}} ; S=\frac{2 \sigma}{p_{0} R_{0}} ; R e=\frac{a_{*} R_{0}}{4 \nu_{1}} ; P e=\frac{a_{*} R_{0}}{D_{1}} ; \alpha_{20} ; e_{0}=\frac{\rho_{20}^{0}}{\rho_{1}^{0}} ; \gamma ; \\
C_{2^{*}} & =\frac{B T_{0}}{\ell}=\frac{\gamma-1}{\gamma} \frac{c_{p_{2}} T_{0}}{\ell} ; \quad C_{1^{*}}=\frac{c_{1} T_{0}}{\ell} ; \quad \Delta P_{e}=\frac{p_{e}-p_{0}}{p_{0}} ; \quad\left(a_{*}^{2}=\frac{p_{0}}{\rho_{1}^{0}}\right) ;
\end{aligned}
$$

which characterize the influence of the external mass forces $G$, capillary effects $S$, liquid viscosity (the Reynolds number $R e$ ), thermal conductivity (the Peclet number $P e)$, small relative density $e_{0}$ of the vapour, its specific heat ratio $\gamma$, specific heats of the phases and the specific heat of vaporization $C_{2^{*}}, C_{1^{*}}$, and, finally, of the shockwave intensity $\left(\Delta P_{e}\right)$. Here $D_{1}=\lambda_{1} / \rho_{1}^{2} c_{1}$ is the thermal diffusivity of the liquid, the subscript $e$ refers to parameters of the final equilibrium state (behind the wave).

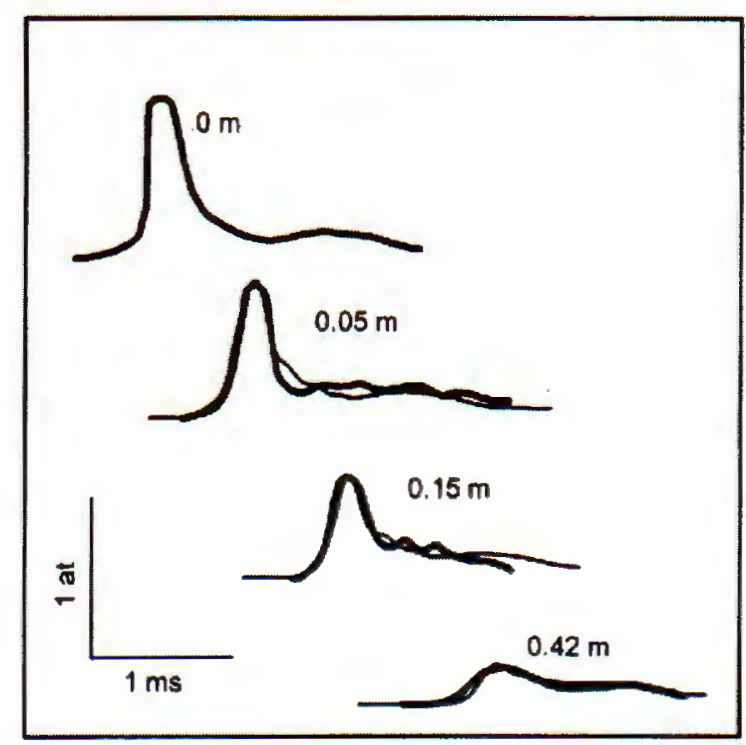

Fig. 1

In Fig. 1 the diagram illustrates a comparison of calculated evolution (thin solid curves) of the short shock waves, where the experimental data by Nakoryakov (1981) are used for doing the initial boundary condition, with experimental pressure profiles in short shock waves by Nakoryakov (1981) (bold solid curves), in the boiling water with vapour bubbles. In this case, the initial conditions and the parameters of the medium structure are as follows: $R_{0}=1.4 \mathrm{~mm} ; p_{0}=5$ at; $\alpha_{20}=0.015$; Curves $1-4$ 
show pressure profiles corresponding to the following coordinates of the shock-tube sections measured from the free surface of the working section: $x=0 ; 0.05 ; 0.15$; $0.42 \mathrm{~m}$. An agreement between the experimental pressure profiles and calculated pressure profiles can be seen.

Fig. 2 - 4 illustrate the evolution of stationary shock wave with moderate intensities in the mixture of boiling water with vapour bubbles. These shock waves propagate in the mixture, act on the solid wall and reflect backwards from it. The vertical axis of graphs is the logarithmic scale, the horizontal axis is the space scale.

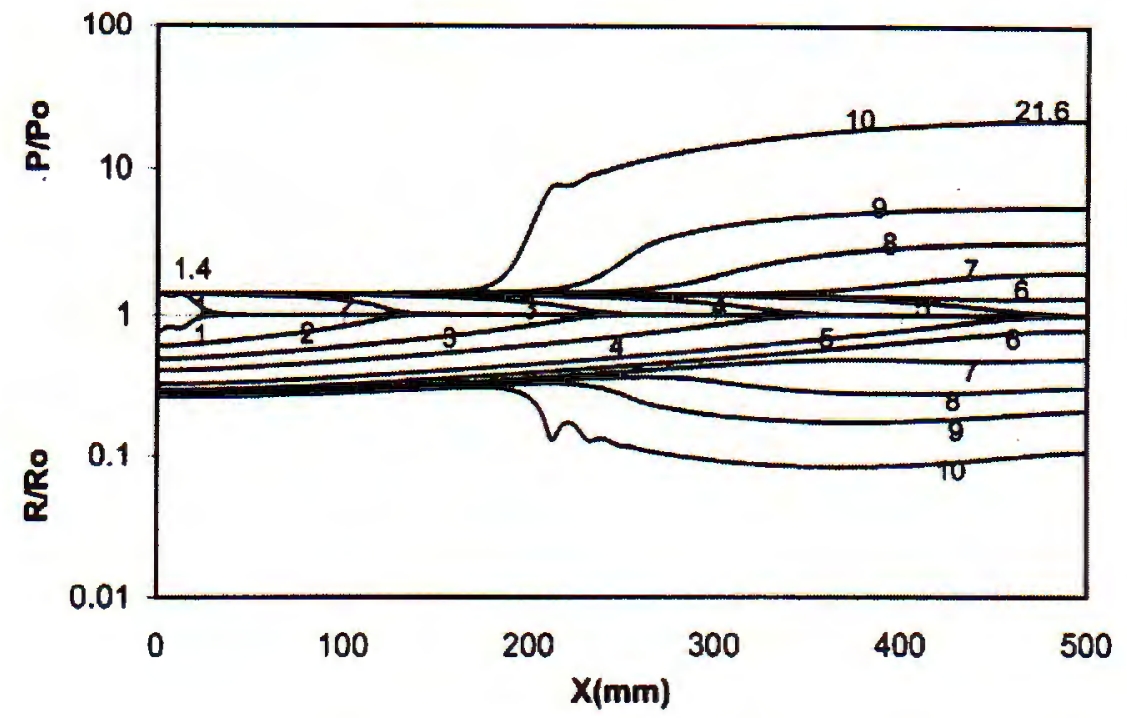

Fig. 2

In Fig. 2 the diagram expresses the evolution of the pressure waves $P$ and the change of the bubble radius $R$ in boiling water with vapour bubbles, which has propagated over distance of $L=0.5 \mathrm{~m}$ (i.e. the distance from $x=0$ to $x=L$, where $L$ is the position of the solid wall and the distance $L$ is understood as the length of the investigation pipe). In this case, the following initial and boundary conditions are used: $p_{0}=1$ at; $R_{0}=1.5 \mathrm{~mm}$; the volume fraction of the vapour phase $\alpha_{20}=5 \%$, at $x=0$ the intensity of long wave $p_{e}=1.4$ at. Curves 1-10 of Fig. 2 correspond to moments of time: $t=0.5 ; 3 ; 6 ; 10 ; 15 ; 16.5 ; 17 ; 17.2 ; 17.4$ and $17.6 \mathrm{~ms}$, respectively. From Fig. 2 it can be seen that the pressure-wave intensity in the mixture after being reflected from the solid wall increases to a value much higher than its initial value. In this example, the reflection pressure on the wall can reach to 21.6 at. At the same time, it is also clear that the incident wave is monotonic, the wave reflected by solid wall appears oscillatory. In the ideal case, when the details of the structures of shock waves are not delved into and the shock-wave propagation is considered as the propagation of discontinuation surface, the reflection pressure on the wall can reach to 22.4 at (for comparison in the case $\alpha_{20}=0 \%$ (pure water), the reflection pressure 
on the wall is received only about 1.8 at) (Duong Ngoc Hai \& Nguyen Van Tuan 2000). This value is higher than the value received above, because it is proposed that in this case a complete condensation of vapour in the bubbles is occurred. It was "idealization". In the case presented above, though the structure of the medium and its compressibility are changed due to the bubble volume decreases, the bubbles yet exist in the medium. Thus, an anomalous increase in intensity of the waves reflected by solid wall in this case is less than in the "idealization" model. From the results presented in Fig. 2 it is also clear that, after being reflected by solid wall, at some moments the bubble radius could decrease to a value of $\lesssim 0.1 R_{0}$.

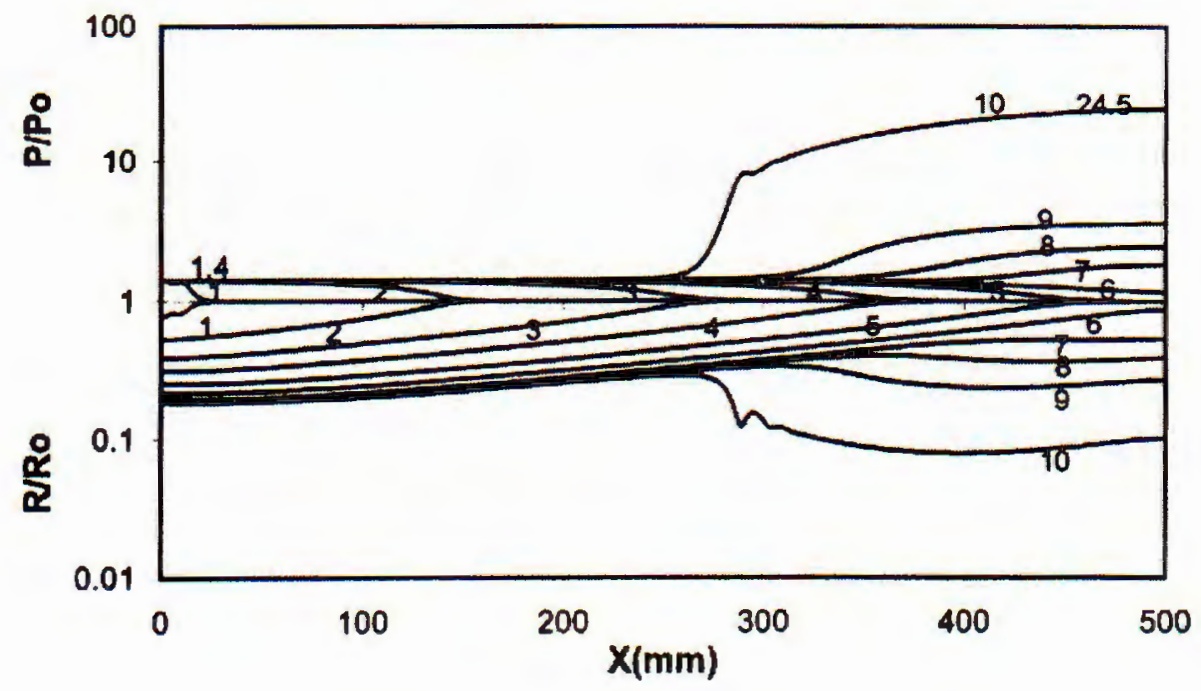

Fig. 3

For the case presented in Fig. 3, the volume fraction of the vapour phase $\alpha_{20}=$ $10 \%$, and the initial, boundary conditions and the other parameters of structure mixture are the same as the case presented in Fig. 2. Curves 1-10 of Fig. 3 show the pressure profiles and the change of the bubble radius corresponding to moments of time: $t=0.5 ; 5 ; 10 ; 16 ; 20 ; 22.5 ; 23.2 ; 23.4 ; 23.5$ and $23.65 \mathrm{~ms}$, respectively. From the results presented in Fig. 3 , the intensity of pressure waves after being reflected from the solid wall can be seen and it can reach to 24.5 at. This result is less than the result calculated using the "idealization" model, when the shock adiabatic analysis is done and the shock wave is considered as a plane, the value of reflection pressure on the wall reached about 31.87 at. Thus, the volume fraction of the vapour phase in the mixture increases, the stronger nonlinearity of the bubbly liquid manifests. Moreover after being reflected by solid wall, at some moments the bubble radius could decrease to a value of about $0.08 \mathrm{~mm}$, which is much smaller than value of the bubble initial radius.

From the results presented in Fig. 2 - 3 it can be clear that the volume fraction of the vapour phase in the mixture influences on the intensities of the waves reflected 
by the solid wall. It will increase when the volume fraction of the vapour phase in the mixture increases. The volume fractions of the vapour phase in the mixture equal $5 \%$ and $10 \%$, the values $\Delta n$ equal 50 and 58 , respectively, where $\Delta n=\frac{\Delta p^{(2)}}{\Delta p^{(1)}}$; $\Delta p^{(2)}=p_{r e}-p_{e} ; \Delta p^{(1)}=p_{e}-p_{0} ; p_{r e}$ is value of reflection pressure on the solid wall.

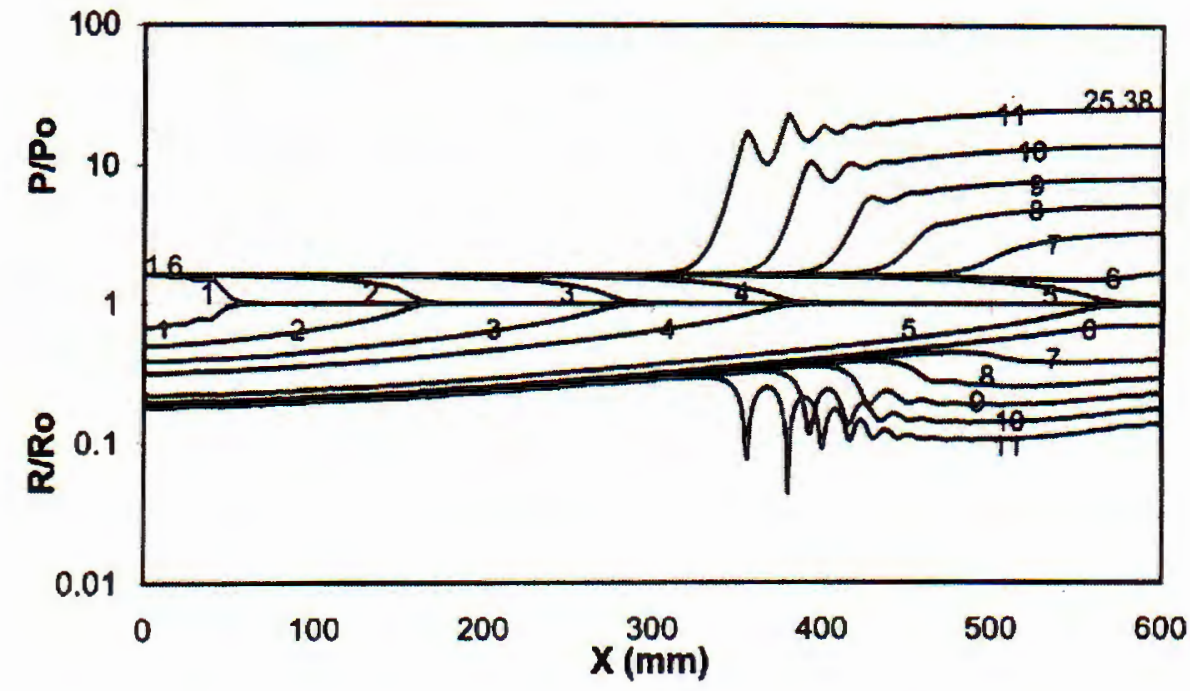

Fig. 4

Curves 1-11 in Fig. 4 show the pressure profiles and the change of the bubble radius corresponding to moments of time: $t=1 ; 3.5 ; 6.5 ; 9 ; 14 ; 15.5 ; 16.3 ; 16.5$; $16.62 ; 16.68$ and $16.72 \mathrm{~ms}$, respectively. In this case, the following initial and boundary conditions are used: $p_{0}=1$ at; $R_{0}=1.5 \mathrm{~mm} ; L=0.6 \mathrm{~m} ; \alpha_{20}=5 \% ; p_{e}=1.6$ at. From the results presented in Fig. 4, the pressure-wave intensity after being reflected from the solid wall can be seen and in this case it can reach to 25.38 at. This result is less than the result calculated using the "idealization" model, because in the "idealization" model the value of the reflection pressure on the wall reached about 27.31 at. At the same time, from Fig. 4 it is also clear that the incident wave is monotonic, the wave reflected by solid wall appears oscillatory. Moreover, after being reflected by the solid wall, at some moments the bubble radius could decrease to a value of about $0.043 \mathrm{~mm}$. Thus, when the intensity of initial shock increases, the amplitude of oscillations of the bubble radius in the mixture will considerably increase (see Fig. 4).

In Fig. 5 the diagram illustrates the evolution of pressure waves in boiling water with vapour bubbles, which has propagated over distance of $L=1 \mathrm{~m}$. In this case, the initial shock intensity acting on the mixture is changed, it receives two values 1.4 at and 1.2 at. The following initial conditions are used: $p_{0}=1$ at; $R_{0}=$ $1.5 \mathrm{~mm} ; \alpha_{20}=5 \%$. Solid curves $1-9$ show the pressure profiles for the case $p_{e}=$ 
1.4 at corresponding to moments: $t=0.5 ; 10 ; 15 ; 24 ; 32.5 ; 33.11 ; 33.24 ; 33.37$ and $33.49 \mathrm{~ms}$. Curves $1-8$ marked by the small lozenges show the pressure profiles for the case $p_{e}=1.2$ at corresponding to times: $t=0.5 ; 10 ; 24 ; 38 ; 47.64 ; 48.06 ; 48.19$ and $48.33 \mathrm{~ms}$, respectively. From the results presented in Fig. 5 it is seen that for the initial shock-wave intensities $p_{e}=1.4$ at and $p_{e}=1.2$ at, the reflection-wave intensities on the wall can reach to 14.8 at and 3.8 at, respectively, or $\Delta n$ equal 33.5 and 13, respectively. Thus, a small change of the initial shock intensity will lead to a big change of the reflection-wave intensities, it manifests a stronger nonlinearity of the bubbly liquids. From the results presented in Fig. 5, it is also seen that not only the initial shock intensity, but also the length of the investigation pipe influences the reflection-wave intensities. Within unsteady wave length the reflection-wave intensities will decrease while the pipe increases. However, for the length of the investigation pipe is big enough ( $\left.L>0.7 \mathrm{~m} ; p_{e} \leq 1.4 \mathrm{at}\right)$, the intensity values of the reflection pressures on the wall receive almost invariable. The difference of velocity waves in the cases presented above are estimated by duration of the propagation waves in the over length of investigation pipe.

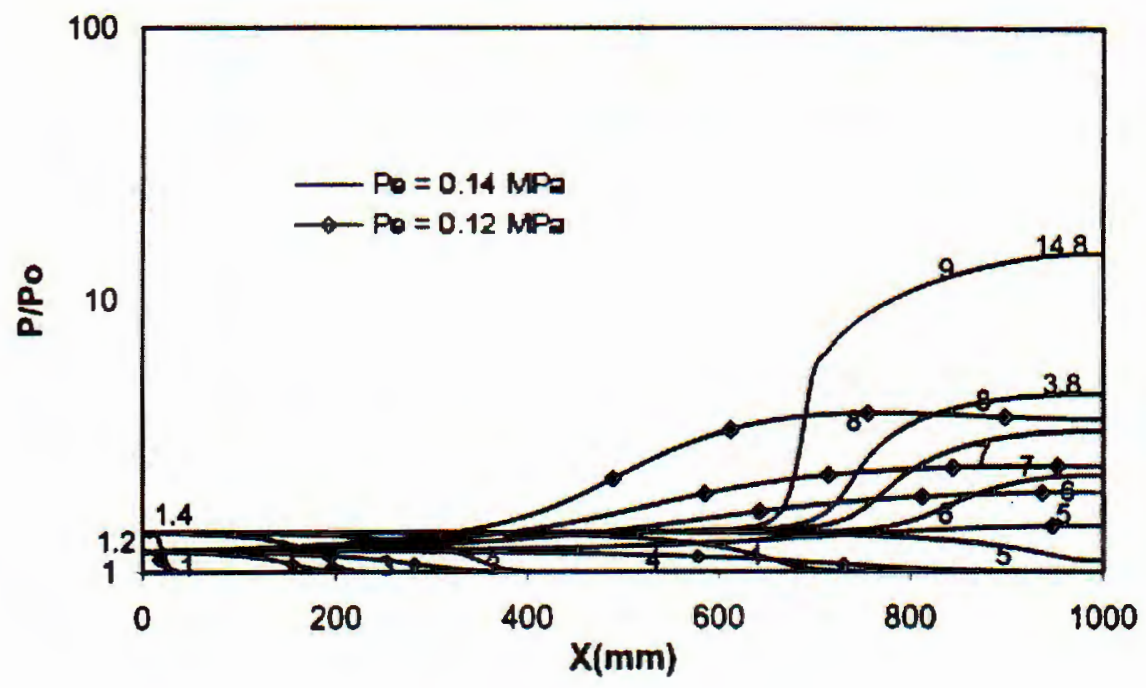

Fig. 5

Fig. 6 - 7 illustrate the evolution of a delta-pulse in boiling water with vapour bubbles. This shock pulse propagates in the mixture over the distance $0.4 \mathrm{~m}$, acts on the solid wall, reflects backwards from it. In these cases, the duration $t_{0}$ of the initial shock pulses acting on the mixture are changed, the following initial and boundary conditions are used and fixed: $p_{0}=1$ at; $R_{0}=1.5 \mathrm{~mm}$; the volume fraction of the vapour phase $\alpha_{20}=5 \%$, at $x=0$ the pulse intensity $\Delta P_{\max }=1$, (where $\Delta P_{\max }=\frac{p_{\max }-p_{0}}{t_{0}}$ ). In the first case $t_{0}=t_{1}=t_{2}=2 \mathrm{~ms}$ (shown in Fig. 6) and in the second case $t_{0}=t_{1}=t_{2}=1 \mathrm{~ms}$ (shown in Fig. 7), where $t_{1}$ and $t_{2}$ constants are determined by duration of the initial pulse. Solid curves $1-17$ show the pressure 
profiles corresponding to times: $0.5 ; 0.8 ; 1.4 ; 2 ; 2.8 ; 3.2 ; 3.6 ; 4 ; 4.6 ; 5.4 ; 6.4 ; 7.6 ; 8.7$; $9.7 ; 10.2 ; 11$ and $12 \mathrm{~ms}$, respectively. The shock-wave intensity after being reflected from the solid wall is just about 1.28 at (see Fig. $\dot{6}$ ). Solid curves $1-18$ show the pressure profiles corresponding to times: $0.5 ; 0.7 ; 1 ; 1.2 ; 1.4 ; 1.6 ; 1.8 ; 2 ; 2.3 ; 2.8 ; 3.5$; $4.3 ; 5.5 ; 7 ; 9 ; 10 ; 12$ and $13 \mathrm{~ms}$, respectively. The shock-wave intensity after being reflected from the solid wall is just about 1.1 at (see Fig. 7).

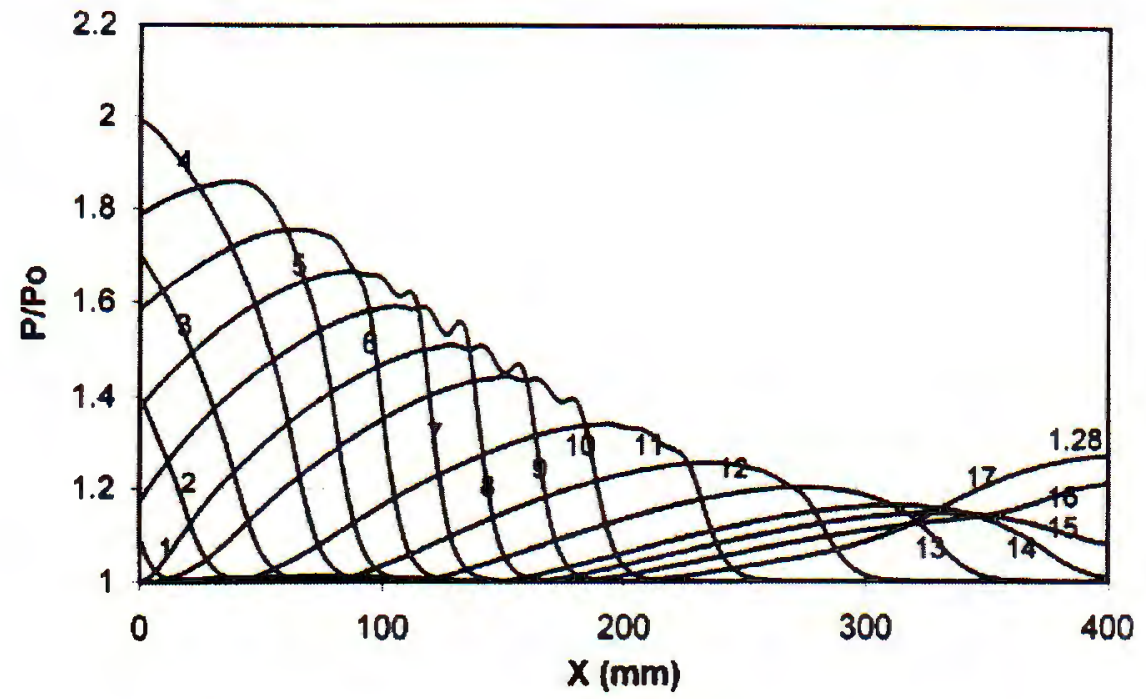

Fig. 6

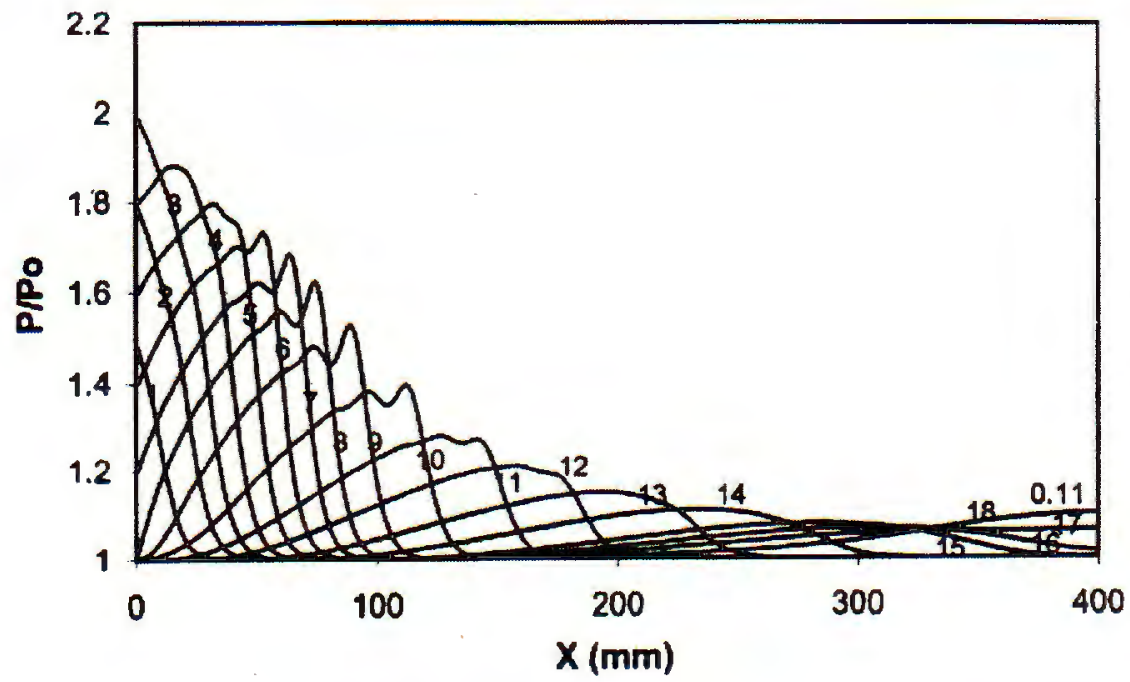

Fig. 7

From the results presented in Fig. 6 - 7, it can be seen that the intensity of the waves reflected by the solid wall will increase when the duration of initial shock pulse increases. However, the received value of reflection pressure on the solid wall 
is small, because the delta-pulse propagation in the mixture can be transformed into solitary waves and the pulse amplitude will be stronger damp owing to the significant influence of the interphase heat and mass transfer (Nigmatulin et al 1988).

\section{Conclusion}

Based on the presented model, to calculate the shock-wave propagation and reflection by wall in the mixture of liquid with vapour bubbles, the algorithm was selected and the numerical code was constructed and built. The code was verified by comparing obtained results with some experimental and published results for incident waves of the other authors. This code was used for investigating the waves reflected by solid wall in the mixture of boiling water with vapour bubbles. Based on the obtained results, the following conclusions can be drawn:

Beside the types of material (e.g. water, oil, nitrogen...etc.), the behaviour of the shock wave, after being reflected from the solid wall, strongly depends on the volume fraction of the vapour phase in the mixture, the initial shock intensity and weakly changes in dependence on the size of bubbles.

In comparison with waves reflected by solid wall in pure liquid, the intensity of the waves reflected by solid wall in the liquid with vapour bubbles is many times greater (e.g. $10-15$ times for $\alpha_{20} \approx 5 \%, p_{e}=1.4$ at).

The reflection pressure on the wall will increase when the volume fraction of the vapour phase in the mixture or the initial shock intensity increases. In some cases, the strong nonlinearity of the process can lead to that although the incident waves may have the monotonic structures, but the waves reflected by solid wall appear oscillatory.

In the case of the pulse pressure propagation in the mixture, not only the intensity of the initial pulses, but also the duration of the initial shock pulses acting on the mixture influences on the intensity of the reflection pressure on the wall. The value of the reflection pressure on the wall will increase when the duration of the initial shock pulse increases. However, the value of the intensity of the reflection pressure on the wall normally is inconsiderable because during the pulse propagation in the medium, its intensity rapidly decreases before its reflection backwards.

The research is completed with partly financial support of Vietnam Foundation of Natural Sciences, to which the authors would like to express their sincere thanks.

\section{REFERENCES}

1. Dontsov V. E., Pokusaev B. G. Experimental study of gas solution behind a shock wave in liquid with bubbles of easily soluble gas. Proc. of Int. Conf. on Multiphase Flow ICMF' 98. Lyon, France, 1998.

2. Drumheller D. S., Kipp M. E. and Bedford A. Transient wave propagation in bubbly liquids. J. Fluid Mech. Vol. 119, 1982, 347-365. 
3. Duong Ngoc Hai, Nigmatulin R. I. and Khabeev N. S. Structure of shock waves in liquid with vapour bubbles. Izv. Acad. Nayk. SSSR, Mechanics of Gas and Fluid, No 2, 1982, 109-118.

4. Duong Ngoc Hai. Shock wave in liquid with bubbles of gas or vapour. J. Mechanics Vol. 4, 1987, 3-8.

5. Duong Ngoc Hai and Nguyen Van Tuan: Shock adiabat analysis for the mixture of liquid and gas two components. J. Mechanics Vol.22. No 2, 2000, 101-110.

6. Fujii $T$. et al. Water hammers phenomena in one-component two-phase bubbly flow. Proc. of the Int. Conf. on Multiphase Flow' 91- Tsukuba, Japan, 1991.

7. Gubaigullin A. A., Beregova O. Sh. and Bekishev S. A. Shock waves in nonNewtonian bubbly liquids. Int. J. Multiphase Flow Vol. 27, 2001, 635-655.

8. Kashinsky O. N., Randin V. V. and Chinak A. V. Liquid velocity and wall shear stress in bubbly flows. Proc. of the Int. Conf. on Multiphase Flow' 98- France 1998.

9. Kwidzinki R., Karda D. and Pribaturin N. A. Experimental investigation of structure of stationary shock wave and its interaction with transient impulse of pressure in two-phase flow. Proc. of Int. Conf. on Multiphase Flow ICMF' 98 . Lyon, France, 1998.

10. Nakoryakov V. E. Hydrodynamics of two phase flows. In: Hydrodynamics and Heat Transfer in one-and Two -Phase Media pp.5-30. Institute of thermal Physics SD Academy of Sciences of the USSR, Novosibirsk. 1981.

11. Nakoryakov V. E., Vasserman E.S., Pokusaev B. G. and Pribaturin N. A. An increase in the amplitude of pressure waves in a vapour-liquid mixture with bubble structure. J. High Temperature, Vol. 32, No. 3, 1994, 386-392.

12. Nigmatulin R. I. Dynamics of Multiphase Media. Hemisphere, publ. Corp., Washington, 1990.

13. Nigmatulin R. I., Khabeev N. S. and Duong Ngoc Hai. Waves in liquid with vapour bubbles. J.Fluid Mech. Vol. 186, 1988, 85-117.

14. Nigmatulin R. I., Khabeev N. S. and Shagapov V. S. Shock waves in a liquid with gas bubbles. Dokl. Akad. Nauk SSSR 214, 1974, 779-782.

15. Nigmatulin R. I., Shagapov V. S. Structure of shock waves in a liquid containing gas bubbles. Izv. Akad. Nauk SSSR, Mekh. Zhid. I Gaza 6, 1974, 30-41.

16. Noordzij L. and Van Wijngaarden L. Relaxation effects, cause by relative motion, on shock waves in gas-bubble/liquid mixtures. J. Fluid Mech. Vol. 66 1974, 115143.

Received July 10, 2002 


\section{SÓNG PHÂN XA BỚI TƯờNG CÚNG \\ TRONG HỖN HỢP CHẤT LÒNG CHỨA BỌT HƠI NƯớC}

Hỗn hợp chất lỏng và chất khí thường gặp nhiều trong tự nhiênn và các quá trình kỹ thuật. Trong bài báo trình bày các kết quả nghiên cứu sự sóng phân xạ từ tường cứng của sóng xung kích và xung áp suất truyền trong chất lơng chứa bọt hơi nước. Đã nghiên cứu ảnh hưởng của các điều kiện đầu và điều kiện biên, cường độ xung kích và thể tích của pha hơi trong hỗn hợp lên quá trình phản xạ từ tường cứng của các sóng xung kích.

\section{MộT SỐ NÉT VỀ CUỘC THI OLYMPIC CO HỌC TOÀN QUỐC LẦN THỨ XIV - 2002}

Cơ quan chư trì: Hội Co học Việt Nam - Bộ Giáo dục và Đào tạo - Hội Sinh viên Việt Nam.

Ngày thi: 12/5/2002 (Đồng thời tại 3 địa điểm)

Trường dăng cai: - ĐH Giao thông - Vận tải Hà Nội

- ĐH Kỹ thuật Đà Nắng - ĐH Đà Nẵng

- ĐH Giao thông - Vận tải cơ sở 2 TP. Hồ Chí Minh

Môn thi: Cơ lý thuyết, Sức bền vật liệu, Cơ học kết cấu, Thủy lực, Co học đất, Nguyên lý máy, Chi tiết máy (môn Chi tiết máy: lần đầu tiên).

Trường ban tổ chức: PGS TSKH Vũ Duy Quang

Ban giám kháo 7 môn: 179 GS, PGS, TSKH, TS, ThS.

Số trường tham gia: 19 trong đó 11 trường phía Bắc, 7 trường phía Nam và 1 trường ở Đà Nẵng (tăng 1 trường so với năm ngoái)

Tổng số thí sinh dự thi: 690 (tăng 81 thí sinh so với năm ngoái) Tông số giải thường:

\begin{tabular}{|c|c|c|c|c|c|c|}
\hline \multicolumn{4}{|c|}{ Cá nhân } & \multicolumn{3}{|c|}{ Đồng đội } \\
\hline I & II & III & $\mathrm{KK}$ & I & II & III \\
\hline- & - & - & - & $\overline{-}$ & - & - \\
\hline 12 & 34 & 83 & 89 & 7 & 8 & 8 \\
\hline
\end{tabular}

Chiếm tỷ lệ: $35 \%$

Tài trợ cho tổ chức và giải thường: $15 / 19$ trường Đại học có sinh viên dự thi, 8 Hội cơ học chuyên ngành thuộc Hội Cơ học Việt Nam, Liên hiệp các hội KHKT Việt Nam, Quỹ VIFOTEC, Đại học Quốc gia Hà Nội, Chương trình NCCB ngành Co học, Viện Cơ học Hà Nội, Công ty FPT, Cty Hài hòa, TCty TEDI, TCty đầu tư và phát triển Nhà và Đô thị Bộ Xây dựng, Cty Hà Đô. 